\title{
Seeding performance of air-assisted centralized seed-metering device for rapeseed
}

\author{
Xiaolong Lei ${ }^{1,2 *}$, Hongji Hu${ }^{1}$, Wenhao Yang ${ }^{1}$, Liyang Liu ${ }^{1}$, Qingxi Liao ${ }^{3}$, Wanjun Ren ${ }^{2}$ \\ (1. College of Mechanical and Electrical Engineering, Sichuan Agricultural University, Ya'an 625014, Sichuan, China; \\ 2. Crop Ecophysiology and Cultivation Key Laboratory of Sichuan Province, Chengdu 611130, China; \\ 3. College of Engineering, Huazhong Agricultural University, Wuhan 430070, China)
}

\begin{abstract}
In order to analyze seed movement characteristics and improve seeding quality of air-assisted centralized metering device for rapeseed, the effects of the model-hole structure on seed feeding performance were investigated using EDEM simulation. Furthermore, the CFD-DEM coupling approach was applied to determine movement trajectories and airflow fields. The impacts of rapeseed varieties and rotational speed on seeding performance were investigated by bench tests. The results showed that the seed feeding quantity increased with the increase of model-hole's length, depth and section size. Under the model-hole's depth of $3.0 \mathrm{~mm}$, the type II model-hole and model-hole's length of $10 \mathrm{~mm}$, both the variation coefficient of seed feeding quantity and hill diameter were lower which meet the seeding quantity requirement of 2 seeds in each hill. It was revealed that the seed population migrated in a large airflow velocity area and the distribution was uniform. The bench tests indicated that rapeseed varieties and rotational speed had a significant effect on the seed feeding quantity in each hill at rotational speed of 10-40 r/min. The variation coefficient of seed feeding quantity in each hill was less than $17.0 \%$ for each treatment. The hill diameter, which did not exceed $3.5 \mathrm{~cm}$, tended to reduce with increasing rotational speed. The variation coefficient of seeding quantity in each row and seeding uniformity was less than $6.5 \%$ and $32.0 \%$, respectively. Field experiments demonstrated that the seedling was 9-13 plants per meter each row for three rapeseed varieties. The variation coefficient of plants was less than $25.0 \%$ for six rows and their yields reached $2761 \mathrm{~kg} / \mathrm{hm}^{2}$, which realized the mechanized planting requirements. The results can optimize structure of an air-assisted centralized metering system and improve seeding performance.
\end{abstract}

Keywords: rapeseed, air-assisted centralized metering device, seed hill feeding, seeding performance DOI: $10.25165 /$ j.ijabe.20211405.5349

Citation: Lei X L, Hu H J, Yang W H, Liu L Y, Liao Q X, Ren W J. Seeding performance of air-assisted centralized seed-metering device for rapeseed. Int J Agric \& Biol Eng, 2021; 14(5): 79-87.

\section{Introduction}

Rapeseed, which is one of the most significant oil crops in China, is sown in autumn ${ }^{[1,2]}$. Almost $90 \%$ planting area is located in the Yangtze River basin. Due to limited conditions of clay soil, continuous rainfall during seeding period, and small and scattered sloping fields, the rate of mechanized cultivation is only $30 \%$ in the Yangtze River basin for rapeseed. To improve agricultural modernization and the rapeseed industry, the rate of mechanization cultivation will reach $50 \%$ by 2025 according to the document of Guiding Opinion of State Council on Accelerating the Transformation and Upgrading of Agricultural Mechanization and Agricultural Machinery Equipment Industry in China. The seeder

Received date: 2019-08-22 Accepted date: 2021-08-10

Biographies: Hongji Hu, MS candidate, research interests: agricultural mechanization engineering, Email: 1248529386@qq.com; Wenhao Yang, MS candidate, research interests: agricultural mechanization engineering, Email: 1320965043@qq.com; Liyang Liu, MS candidate, research interests: agricultural mechanization engineering, Email: 1272512195@qq.com; Qingxi Liao, $\mathrm{PhD}$, Professor, research interests: rapeseed planting and harvesting technology and equipment, Email: liaoqx@mail.hzau.edu.cn; Wanjun Ren, $\mathrm{PhD}$, Professor, research interests: mechanized planting technology of crops, Email: rwjun@126.com.

*Corresponding author: Xiaolong Lei, PhD, Associate Professor, research interest: mechanized seeding technology and equipment of rapeseed. College of Mechanical and Electrical Engineering, Sichuan Agricultural University, Ya'an 625014, China. Tel: +86-15927368723, Email: leix11989@163.com. with excellent performance is a direct way to increase planting mechanization rate. In order to adapt to the agronomic requirements and geographical conditions in hilly areas, rapeseed seeders with the characteristics of low mass, simplicity, precision and integration should be designed.

The metering device is the core component of rapeseed seeder. There are mainly two types of metering devices, including single-row metering device and centralized metering device. Due to the advantages of multi-rows seeding, adjustable width, high working speed, and fast loading and unloading of seeds, the air-assisted centralized seed-metering device has been a typical metering device by sowing multiple rows in the western counties ${ }^{[3]}$.

The air-assisted centralized seed-metering device has been widely applied in the sowing of wheat, rice, rapeseed, and other crops. It is a core component of large-scale no-tillage seeder produced by many companies, such as John Deere of Unites States, Amazone of Germany, and Maschio of Italy, etc. The structure and seeding performance of the air-assisted centralized seed-metering device were investigated in previous studies. Yatskul et al. ${ }^{[4,5]}$ studied the distribution uniformity of outlet dividers using the Kuhn seeder. They revealed that air-seed flow should be divided evenly by the distribution head, and then transported to the soil. Besides, the airflow field was correlated with pipe diameter for air-seeder conveying system. By comparing distribution uniformity of different distribution head's structure, Kumar and Durairaj ${ }^{[3]}$ showed that it was better to have a streamline flow structure for improving distribution uniformity. 
Mudarisov et al. ${ }^{[6]}$ performed tremendous work in the study of a distribution system of a grain seeder. A centralized pneumatic seeding system was designed and the structural parameters of distribution system were optimized for wheat ${ }^{[7,8]}$. The distribution head's airflow field and the effects of seed feeding rate and air velocity on the seeding performance were investigated for different varieties of Medicago sativa, Elymus dahuricus and maize ${ }^{[9,10]}$. In addition, the airflow field and distribution uniformity has been analyzed to optimize structure of air-assisted centralized seed-metering device for several crops ${ }^{[11-15]}$.

In our group's previous research, the air-assisted centralized seed-metering device was designed for rapeseed and wheat ${ }^{[16]}$. The airflow field distribution and seed motion characteristics in venturi feeding device, seed conveying tube, pressurized tube and distribution were investigated based on CFD-DEM coupling approach, and structural parameters were optimized ${ }^{[17-21]}$. The seed characteristics and working principles were investigated by numerical simulation, bench test, and field experiments.

The main researches of air-assisted centralized seed-metering device were focused on the structural design, experiment optimization and airflow field analysis. However, the seed distribution was complicated due to the impacts of continuous seed feeding, airflow disturbance, and collision between seeds and wall surface on seeding performance. The seeding performance of air-assisted centralized seed-metering device needs to be further improved to meet the agronomic requirements. In this work, we optimized the structure of the seed feeding device to form hill feeding and analyzed seed feeding and distribution characteristics by CFD-DEM coupling simulation. The seeding performance was investigated by bench tests and field experiments. These results would help determine the structural parameters of air-assisted centralized seed-metering device and improve the seeding precision.

\section{Structure and working principle of air-assisted centralized seed-metering device}

\subsection{Structure of air-seeder}

The air-seeder (Figure1), designed by our research group, was comprised of rotary tillage system, air-assisted centralized seed-metering device, fertilizer metering device, air pump and furrow ditching device. The air pump supplied the positive and high-pressure airflow for the air-assisted centralized seed-metering device and fertilizer metering device. The seedbed was leveled by the rotary tillage system for uniform seedling emergence and the ditch was produced by the furrow ditching device. The six rows' seeds were sowed by the air-assisted centralized seed-metering device. The processes of rotary tillage, precision seeding, fertilizing, riding ditch and chemical weeding were accomplished simultaneously for the air-assisted seeder.

The air-assisted centralized seed-metering device (Figure 2), which included seed hill-feeding device, venturi feeding device, seed conveying tube, pressurized tube, distribution head and seed tube, was the core device of the planter for rapeseed. The seeds of six rows were provided by the seed hill-feeding device. When the seed population dropped into a venturi feeding device, the seeds were picked up by the airflow, and then the seeds were mixed with airflow in the seed conveying tube and pressurized tube. After that, the seed population was migrated to the distribution head and seeds were divided into six parts for six rows with an equal probability. The seeds of each outlet reached the soil through a seed tube.

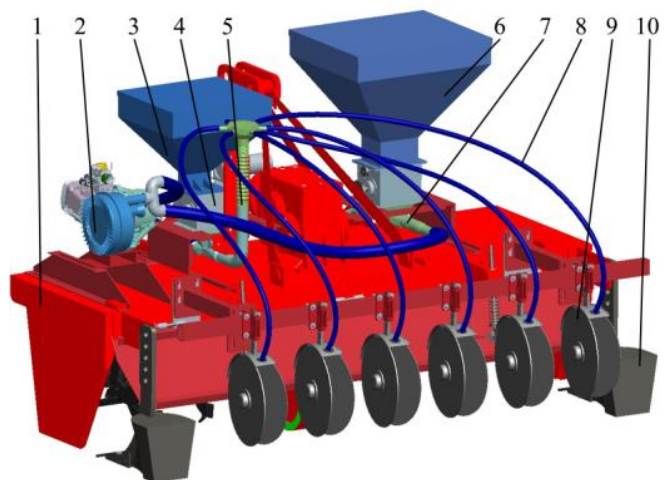

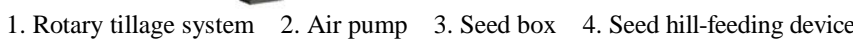
5. Seed distribution system 6. Fertilizer box 7. Fertilizer metering device 8. Seed tube 9. Disk opener 10. Furrow ditching device

Figure 1 Structure of air-seeder for rapeseed

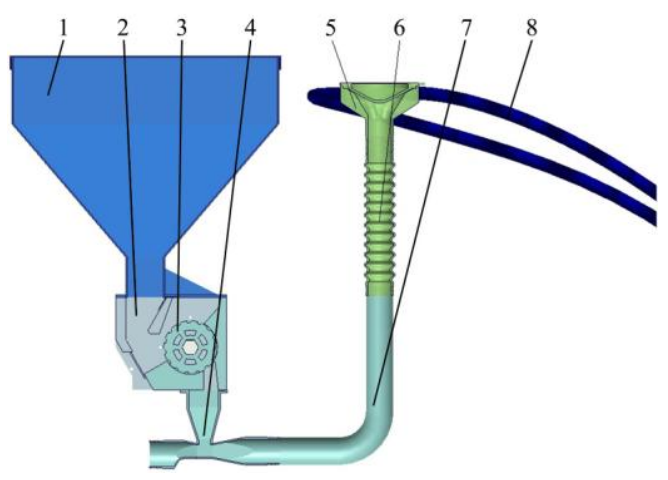

1. Seed box 2. Seed hill-feeding device 3. Seed feeding wheel 4. Venturi feeding device 5. Distribution head 6. Pressurized tube 7. Seed conveying tube 8 . Seed tube

Figure 2 The schematic sketch of air-assisted centralized seed-metering device

\subsection{Design of seed hill-feeding device}

The model-hole had remarkable influence on the performance of seed filling, conveying, protecting and throwing in the seed hill-feeding device. The effects of the parameters of model-hole on the processes of seed filling and throwing were studied using EDEM simulation.

\subsubsection{Simulation model}

The simulation model as shown in Figure 3 is simplified into three parts, namely shell, seed feeding mechanism, and transportation belt. The materials of shell and seed feeding mechanism were aluminum alloy and ABS (acrylonitrile butadiene styrene copolymer), respectively. The transportation belt was applied to transport seeds to determine the positions of seeds with the material of plastic. The hard sphere model and Hertz-Mindlin (no slip) model were chosen as particle model and particles contact model in the EDEM software for rapeseed. Some of the main parameters used in CFD-DEM coupling simulation were listed in Table 1 .

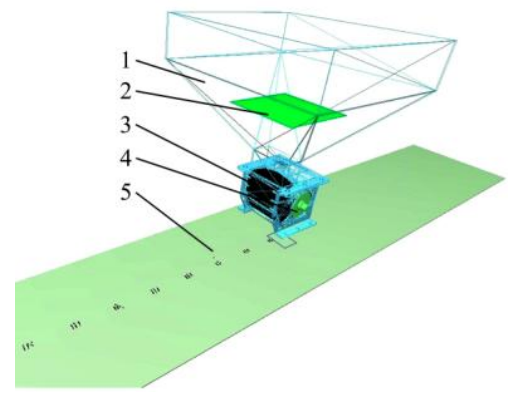

1. Shell 2. Particle factory 3. Rapeseed 4. Seed feeding mechanism 5. Transportation belt

Figure 3 EDEM simulation model 
Table 1 Values of computational parameters used in EDEM

\begin{tabular}{|c|c|c|}
\hline Properties & Parameter & Value \\
\hline \multirow{5}{*}{ Seed properties } & Particle type & Spherical \\
\hline & Diameter/mm & $2.00 \pm 0.20$ \\
\hline & Density $/ \mathrm{kg} \cdot \mathrm{m}^{-3}$ & 1060 \\
\hline & Poisson's ratio & 0.25 \\
\hline & Shear modulus/Pa & $1.1 \times 10^{7}$ \\
\hline \multirow{3}{*}{$\begin{array}{c}\text { Aluminum alloy } \\
\text { properties }\end{array}$} & Density $/ \mathrm{kg} \cdot \mathrm{m}^{-3}$ & 2700 \\
\hline & Poisson's ratio & 0.30 \\
\hline & Shear modulus/Pa & $2.7 \times 10^{10}$ \\
\hline \multirow{3}{*}{ ABS properties } & Density $/ \mathrm{kg} \cdot \mathrm{m}^{-3}$ & 1060 \\
\hline & Poisson's ratio & 0.394 \\
\hline & Shear modulus/Pa & $8.96 \times 10^{8}$ \\
\hline \multirow{3}{*}{ Plastic properties } & Density $/ \mathrm{kg} \cdot \mathrm{m}^{-3}$ & 1350 \\
\hline & Poisson's ratio & 0.47 \\
\hline & Shear modulus/Pa & $2.9 \times 10^{9}$ \\
\hline \multirow{3}{*}{ Seed to seed } & Coefficient of restitution & 0.60 \\
\hline & Coefficient of static friction & 0.50 \\
\hline & Coefficient of rolling friction & 0.01 \\
\hline \multirow{3}{*}{$\begin{array}{l}\text { Seed to aluminum } \\
\text { alloy }\end{array}$} & Coefficient of restitution & 0.60 \\
\hline & Coefficient of static friction & 0.30 \\
\hline & Coefficient of rolling friction & 0.01 \\
\hline \multirow{3}{*}{ Seed to ABS } & Coefficient of restitution & 0.75 \\
\hline & Coefficient of static friction & 0.30 \\
\hline & Coefficient of rolling friction & 0.01 \\
\hline \multirow{3}{*}{ Seed to plastic } & Coefficient of restitution & 0.0001 \\
\hline & Coefficient of static friction & 10 \\
\hline & Coefficient of rolling friction & 10 \\
\hline Gravit & nal acceleration $/ \mathrm{m} \cdot \mathrm{s}^{-2}$ & 9.81 \\
\hline
\end{tabular}

Note: The mechanical parameters between seeds and plastic are set for the convenience of fixing the seed position point, which is not the true value.

\subsubsection{Simulation method}

The shape and size of model-hole are the main factors affecting the seed filling performance. The involute model was used to improve the seed filling performance in previous research $^{[22]}$. There were three factors affecting model-hole, including length of model-hole, section of model-hole and depth of model-hole. For further optimizing structural parameters, the length of model-hole was $10 \mathrm{~mm}, 12 \mathrm{~mm}$ and $14 \mathrm{~mm}$ and the depth of model-hole included $2.5 \mathrm{~mm}, 3.0 \mathrm{~mm}$ and $3.5 \mathrm{~mm}$, respectively. Furthermore, there were three types of section of model-hole that regulated the position of the involute curve, as shown in Figure 4. In the simulation, the rotational velocity and theoretical hill spacing were $20 \mathrm{r} / \mathrm{min}$ and $100 \mathrm{~mm}$, respectively.

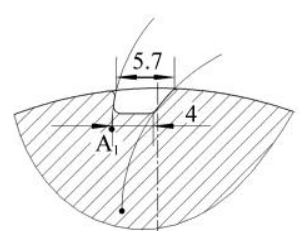

a. Type I

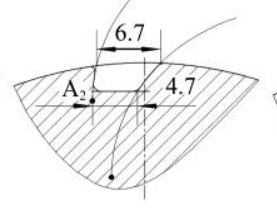

b. Type II

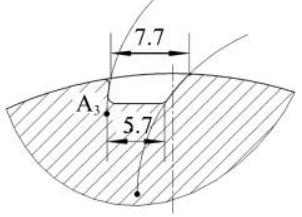

c. Type III
Figure 4 Section sizes of different model-holes (mm)

The simulation design was conducted by the orthogonal design, and the experimental factors and levels were shown in Table 2. The seed feeding quantity, variance coefficient of seeds' quantity, hill spacing, vertical hill diameter and variance coefficient of hill spacing were measured. The methods for measuring hill spacing and vertical hill diameter are illustrated in Figure 5.

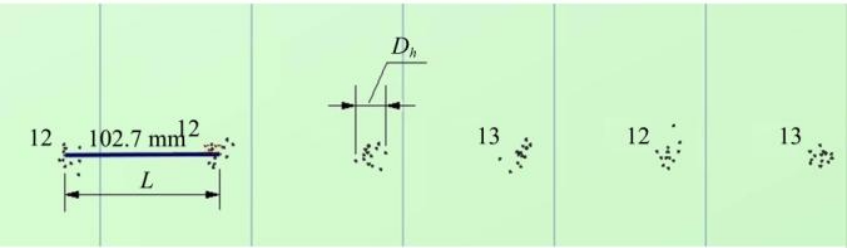

Note: $D_{h}$ and $L$ are vertical hill diameter and hill spacing, respectively.

Figure 5 Test methods of vertical hill diameter and hill spacing on the belt

Table 2 Test factors and levels

\begin{tabular}{cccc}
\hline \multirow{2}{*}{ Levels } & \multicolumn{3}{c}{ Test factors } \\
\cline { 2 - 4 } & $\begin{array}{c}\text { Length of model-hole } \\
\mathrm{A} / \mathrm{mm}\end{array}$ & $\begin{array}{c}\text { Section of } \\
\text { model-hole B }\end{array}$ & $\begin{array}{c}\text { Depth of model-hole } \\
\mathrm{C} / \mathrm{mm}\end{array}$ \\
\hline 1 & 10 & Section I & 2.5 \\
2 & 12 & Section II & 3.0 \\
3 & 14 & Section III & 3.5 \\
\hline
\end{tabular}

2.2.3 Simulation results and analysis

Effects of length, section size and depth of model-hole on seed feeding quantity were significant, as shown in Table 3 . With the increase of length, section size and depth of model-hole, the seed feeding quantity increased. It revealed that the model-hole depth had a significant influence on the variance coefficient of seed feeding quantity, and the variance coefficient of seed feeding quantity was lower at the depth of model-hole of $3.0 \mathrm{~mm}$. Besides, there were obvious differences between the vertical hill diameter and its variance coefficient for each treatment. The depth of model-hole had a significant influence on the vertical hill diameter. There was little difference in hill spacing and its variance coefficient, which meant that the throwing time was consistent.

The results of range analysis showed that the factors affecting the seed feeding quantity were as follows: length of model-hole> depth of model-hole $>$ section of model-hole (Table 4). The orders of effects on variation coefficient of seed feeding quantity and vertical hill diameter were: depth of model-hole > length of model-hole > section of model-hole. The increase of model-hole depth and length resulted in an increase in the seed feeding quantity. According to 2 seeds per hill of agronomic requirement, a lower variation coefficient of seed feeding quantity and vertical hill diameter were obtained with model-hole depth of $3.0 \mathrm{~mm}$ and Section II.

2.2.4 Structural parameters of seed feeding wheel

Model-hole's number was determined by the diameter which was $80 \mathrm{~mm}$. The relationship could be expressed as follows:

$$
N<\frac{\pi D}{2 a}
$$

where, $N$ is the number of model-hole; $a$ is the width of model-hole, $\mathrm{mm} ; D$ is the diameter of the seed feeding wheel, $\mathrm{mm}$.

According to the size and strength of model-hole, the number of model-hole did not exceed 18. For accommodating the working velocity of $2.5-4.5 \mathrm{~km} / \mathrm{h}$ and rotational speed of 10 $50 \mathrm{r} / \mathrm{min}$, the hill spacing should be consistent with working velocity. Thus,

$$
N=\frac{60 v}{b n}
$$

where, $v$ is working velocity of seeder, $\mathrm{m} / \mathrm{s} ; b$ is hill spacing of seeder, $\mathrm{m} ; n$ is the rotational speed of the seed feeding wheel, $\mathrm{r} / \mathrm{min}$.

Based on Equation (2), the number of model-hole was larger 
than 13. By analyzing the hill spacing and model-hole's strength, the number of model-hole was determined as 15 .

Table 3 Experimental design and results

\begin{tabular}{|c|c|c|c|c|c|c|c|c|c|}
\hline \multirow{2}{*}{ Number } & \multicolumn{3}{|c|}{ Factors } & \multirow{2}{*}{$\begin{array}{l}\text { Seed feeding } \\
\text { quantity }\end{array}$} & \multirow{2}{*}{$\begin{array}{l}\text { Variation coefficient of seed } \\
\text { feeding quantity } / \%\end{array}$} & \multirow{2}{*}{$\begin{array}{l}\text { Vertical hill } \\
\text { diameter/mm }\end{array}$} & \multirow{2}{*}{$\begin{array}{l}\text { Variation coefficient of } \\
\text { vertical hill diameter } / \%\end{array}$} & \multirow{2}{*}{$\begin{array}{l}\text { Hill spacing } \\
\text { /mm }\end{array}$} & \multirow{2}{*}{$\begin{array}{l}\text { Variation coefficient of } \\
\text { hill diameter/\% }\end{array}$} \\
\hline & A & B & $\mathrm{C}$ & & & & & & \\
\hline 1 & 1 & 1 & 1 & 10.11 & 12.67 & $24.15 \pm 15.85$ & 65.60 & $100.38 \pm 2.59$ & 2.58 \\
\hline 2 & 1 & 2 & 2 & 14.93 & 7.64 & $22.28 \pm 7.86$ & 35.26 & $100.05 \pm 3.42$ & 3.42 \\
\hline 3 & 1 & 3 & 3 & 17.50 & 23.66 & $35.17 \pm 26.01$ & 73.97 & $99.92 \pm 3.18$ & 3.18 \\
\hline 4 & 2 & 1 & 2 & 12.65 & 9.73 & $20.08 \pm 10.45$ & 52.04 & $100.06 \pm 4.38$ & 4.38 \\
\hline 6 & 2 & 3 & 1 & 16.00 & 9.52 & $44.75 \pm 17.08$ & 38.16 & $100.49 \pm 10.28$ & 10.23 \\
\hline 7 & 3 & 1 & 3 & 21.74 & 15.96 & $56.11 \pm 23.51$ & 41.90 & $99.33 \pm 9.67$ & 9.73 \\
\hline 8 & 3 & 2 & 1 & 18.79 & 5.68 & $38.27 \pm 15.88$ & 41.48 & $100.25 \pm 4.60$ & 4.59 \\
\hline 9 & 3 & 3 & 2 & 20.30 & 7.34 & $34.52 \pm 18.67$ & 54.09 & $100.01 \pm 2.47$ & 2.47 \\
\hline \multirow[b]{2}{*}{$F$ value } & & A & & $18.57 * *$ & 5.50 & 4.21 & 1.01 & 1.28 & 3.91 \\
\hline & & B & & $8.13 *$ & 4.89 & 0.36 & 1.21 & 1.09 & 0.88 \\
\hline
\end{tabular}

Note: $*$ and $* *$ mean significance in variance analysis at the 0.05 and 0.01 probability levels, respectively. The same as below.

Table 4 Analysis of experimental results

\begin{tabular}{|c|c|c|c|c|c|c|c|c|c|}
\hline \multirow{2}{*}{ Items } & \multicolumn{3}{|c|}{ Seed feeding quantity } & \multicolumn{3}{|c|}{ Variation coefficient of seed feeding quantity } & \multicolumn{3}{|c|}{ Vertical hill diameter } \\
\hline & A & $\mathrm{B}$ & $\mathrm{C}$ & A & B & $\mathrm{C}$ & A & B & $\mathrm{C}$ \\
\hline$k_{1}$ & 14.18 & 14.83 & 14.97 & 14.66 & 12.79 & 9.29 & 27.20 & 33.45 & 35.72 \\
\hline$k_{2}$ & 16.94 & 18.63 & 15.96 & 10.92 & 8.95 & 8.24 & 37.19 & 35.77 & 25.63 \\
\hline$k_{3}$ & 20.28 & 17.93 & 20.47 & 9.66 & 13.51 & 17.71 & 42.97 & 38.15 & 46.01 \\
\hline$R$ & 6.10 & 3.79 & 5.50 & 5.00 & 4.56 & 9.48 & 15.77 & 4.70 & 20.38 \\
\hline Optimum level & $\mathrm{A}_{3}$ & $\mathrm{~B}_{2}$ & $\mathrm{C}_{3}$ & $\mathrm{~A}_{3}$ & $\mathrm{~B}_{2}$ & $\mathrm{C}_{2}$ & $\mathrm{~A}_{1}$ & $\mathrm{~B}_{2}$ & $\mathrm{C}_{2}$ \\
\hline Significant order & \multicolumn{3}{|c|}{$\mathrm{A}_{3} \mathrm{C}_{3} \mathrm{~B}_{2}$} & \multicolumn{3}{|c|}{$\mathrm{C}_{2} \mathrm{~A}_{3} \mathrm{~B}_{2}$} & \multicolumn{3}{|c|}{$\mathrm{C}_{2} \mathrm{~A}_{1} \mathrm{~B}_{2}$} \\
\hline
\end{tabular}

\section{Analysis of the distribution process}

\subsection{Simulation model of gas-solid phases}

To investigate the distribution process in distribution head under seed hill feeding and airflow conveying, the simulation was carried out using CFD-DEM coupling approach. The tetrahedral CFD cells were gridded by Workbench 15.0 software with a minimum grid size of $1 \times 10^{-5} \mathrm{~m}$ and a maximum grid size of $4 \times 10^{-5} \mathrm{~m}$. The grid of $3 \mathrm{D}$ model is shown in Figure $6 \mathrm{a}$. In the boundary conditions setting, the velocity-inlet and pressure-outlet

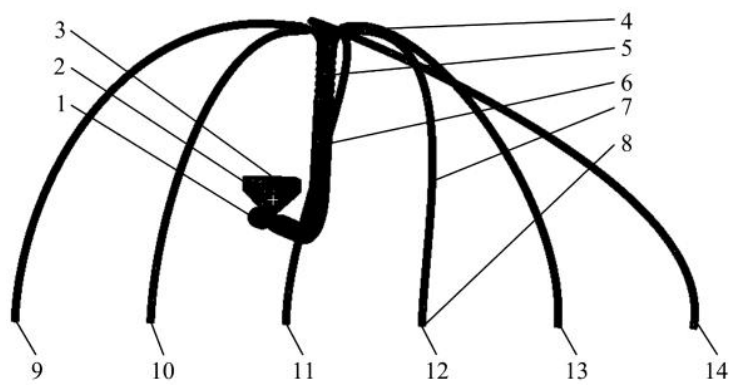

a. CFD-DEM coupling simulation model b. Seeds number and collisions in the simulation model

were applied in all the simulations. The motion of gas phase was solved by using Standard $k-\varepsilon$ two equations turbulence model. Walls were assumed to be made of aluminum alloy, and their positions were fixed. The Lagrangian coupling method was applied in CFD-DEM coupling interface. The EDEM and CFD time steps for satisfactory convergence were selected as $5 \times 10^{-6} \mathrm{~s}$ and $1 \times 10^{-3} \mathrm{~s}$, respectively. The airflow velocity and seed feeding quantity were $20 \mathrm{~m} / \mathrm{s}$ and 12 particles each time, respectively. The mechanical and geometric parameters used in the simulation were derived from previous research ${ }^{[18]}$ and Table 1. 8. Seeds outlet tube $9.1^{\text {st }}$ Row $10.2^{\text {nd }}$ Row $11.3^{\text {rd }}$ Row $12.4^{\text {th }}$ Row $13.5^{\text {th }}$ Row $14.6^{\text {th }}$ Row

Figure 6 Simulation model of air-assisted centralized metering device for rapeseed

\subsection{Analysis of distribution process}

The process of seed motion in an air-assisted centralized metering device is illustrated in Figure 7. First, the seed population entered the venturi feeding device (Figure 7a). Then, the seed population was delivered into delivery tube under the drag force of airflow (Figure 7b). The seeds velocity and force acting on seed increased dramatically in the delivery tube. However, the seed velocity decreased when seed population entered into pressurized tube and the seeds were dispersed (Figure 8). The seed velocity increased in the distribution process and the seed population was separated into 6 parts uniformly while entering the seed tube (Figure 7d). It was observed that the distance between seeds was larger due to the impact of airflow and collisions between seeds and seed tubes. 


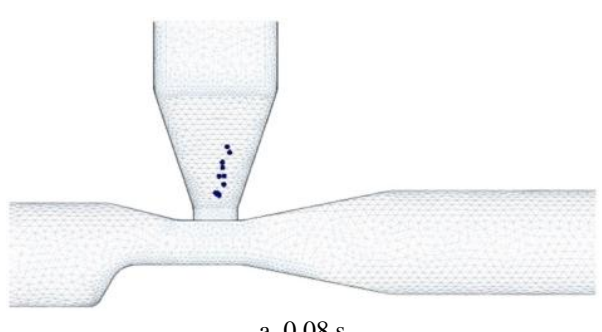

a. $0.08 \mathrm{~s}$

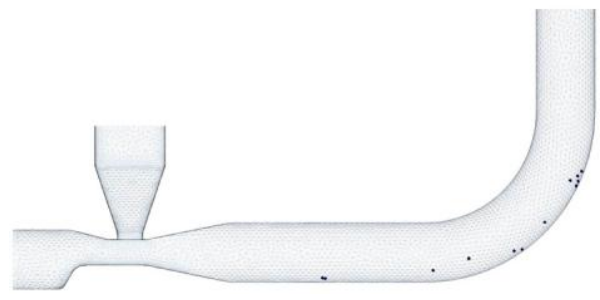

b. $0.15 \mathrm{~s}$

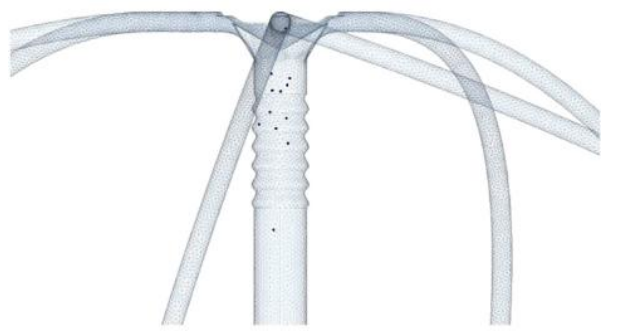

c. $0.23 \mathrm{~s}$

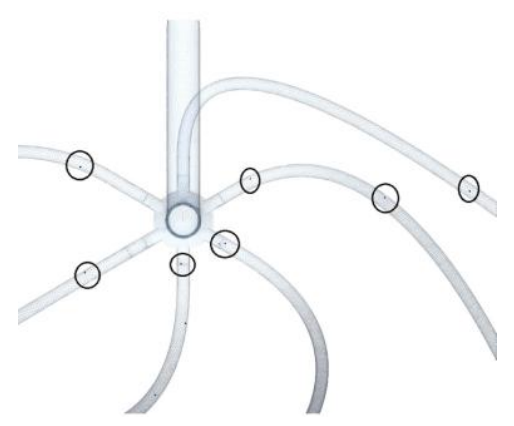

d. $0.35 \mathrm{~s}$

Figure 7 Movement processes of rapeseed

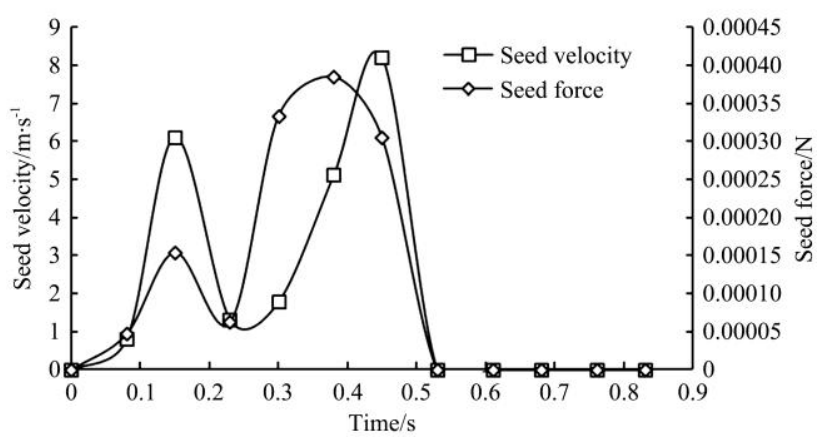

Figure 8 Force and velocity of rapeseed in air-assisted centralized metering device

The pressure and velocity of the airflow field were illustrated in Figure 9. It could be concluded that seeds mainly moved in the high airflow velocity region. The pressure and velocity were distributed uniformly within the pressurized tube airflow field, causing the seeds to enter desperately into distribution head. Besides, the airflow velocity of the outlet was almost consistent, that was why the consistent probability of seed flow entering the seed tube was congruent. From seed movement trajectory in air-assisted centralized seed-metering device, the time was different for various seed tubes when seeds were separated (Figure 10). The seeds number of each outlet was almost identical, which indicated that the seed population could be separated uniformly and the same interval seed benefited hill sowing.

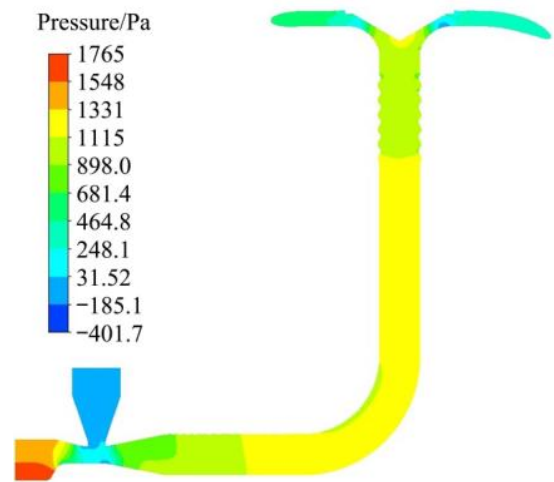

a. Velocity of airflow field

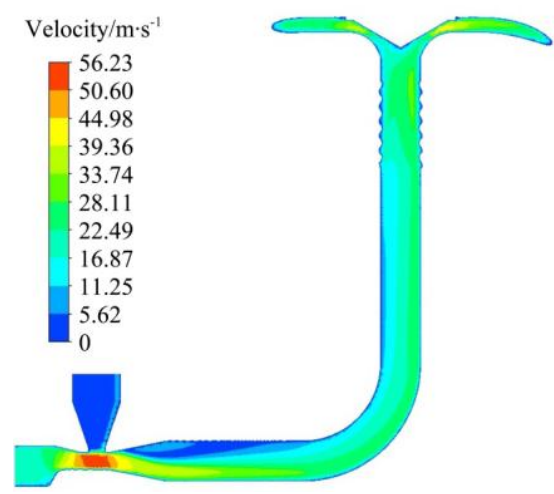

b. Pressure of airflow field

Figure 9 Pressure and velocity of airflow field of air-assisted centralized metering device for rapeseed

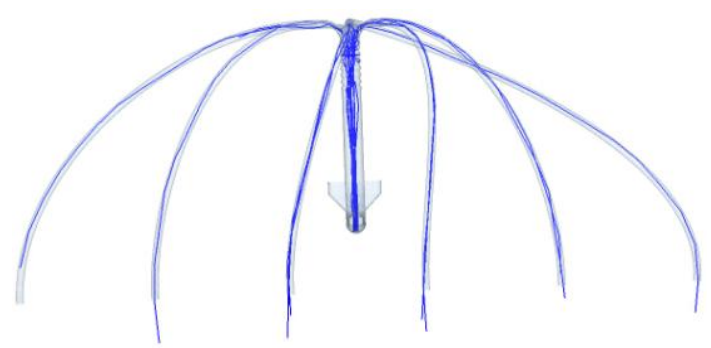

Figure 10 Distribution trajectory of rapeseed

\subsection{Seed motion characteristics in seeding process}

In the seeding process, the motion trajectory and seeds' positions were affected by the interaction between seeds and the seed-metering system. The collisions between seeds and the wall of centralized metering device were shown in Figure 11. Collisions in seed tube were larger than those in distribution head

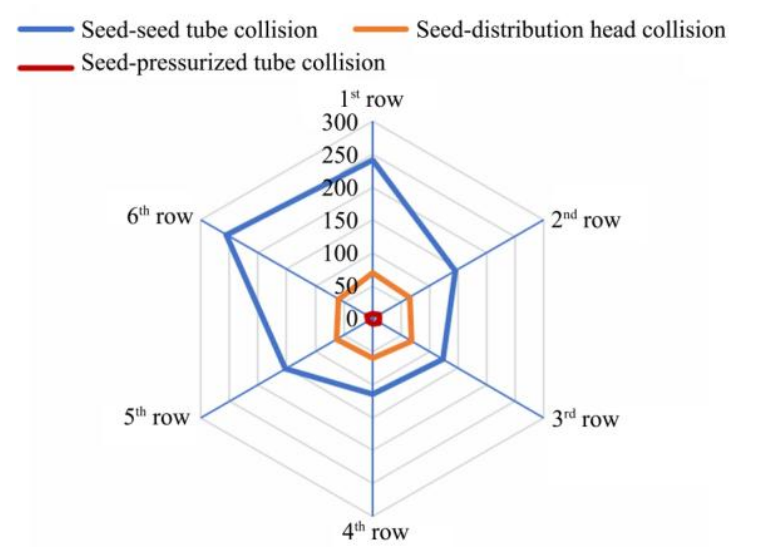

Figure 11 Collisions between seeds and air-assisted centralized metering device 
and pressurized tube. In addition, the collisions in $1^{\text {st }}$ Row and $6^{\text {th }}$ Row were significantly larger than other rows due to the length of seed tubes. There was no obvious difference in collisions in distribution head and pressurized tube. This indicated that seeds could be distributed evenly according to the uniform probability of collisions in the distribution head. The seed locations could be affected by the seed tube because of different collisions between seeds and seed tube.

\section{Seeding performance of bench test}

\subsection{Materials and methods}

In this section, the experimental setup, experiment design and the measurement methods were presented. The research was carried out using an experimental setup (Figure 12). The experimental setup was composed of a JPS-12 seed metering platform and experimental equipment. In the bench test, the seed hill-feeding device was installed on the JPS-12 seed metering platform to test the hill-feeding performance and the air-assisted centralized metering device was mounted on the JPS-12 seed metering platform to determine the seed distribution characteristics. The test seeds provided by the seed hill-feeding device (3) from the seed box were mixed with the airflow and the seed-air two-phase flow was transported and distributed in the seed distribution system (4). The rotational speed was controlled by the gear motor (2) and the oiled belt (6) was utilized to fix the positions of the seeds.

For the seed hill-feeding performance, the rapeseed varieties and rotational speed were tested with the hill-feeding device. The three commonly used rapeseed varieties included Rongyou 11, Zhongshuang 11 and Huayouza 62, and rotational speed was a range of $10-40 \mathrm{r} / \mathrm{min}$ with $10 \mathrm{r} / \mathrm{min}$ intervals. The seed feeding quantity of each hill, vertical hill diameter and hill spacing were measured with taking 50 hills as samples. Variance coefficients of these indexes were calculated. Each test was replicated 3 times.

In the distribution experiment, seeds were collected and weighted from each outlet. The balance was applied with a weight precision of $\pm 0.001 \mathrm{~g}$. All outlets were numbered and the same dispositions of outlets were conserved for three minutes. The variance coefficient of seeding quantity in each row was estimated according to ISO-7256/2 ${ }^{[23]}$. To better demonstrate the distribution performance, the seeds' quantity and position were measured on the JPS-12 seed metering platform. Besides, the variance coefficient of hill spacing was utilized to evaluate the seed position's uniformity.

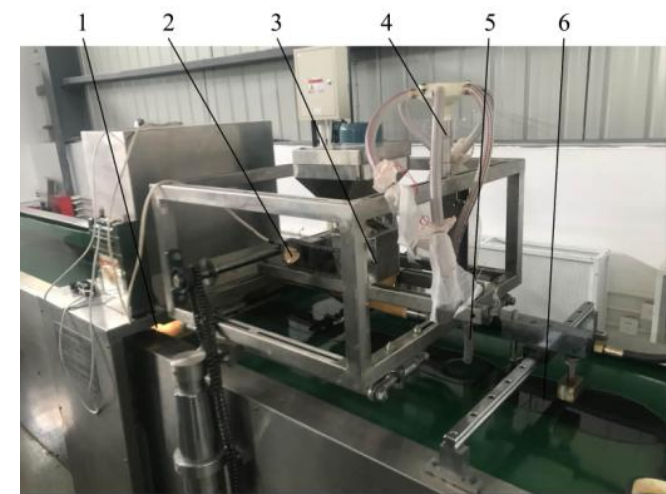

1. JPS-12 seed metering platform 2. Gear motor 3. Seed hill-feeding device 4. Seed distribution system $\quad 5$. Seed tube 6 . Oiled belt

Figure 12 Bench test of seed distribution uniformity

\subsection{Results and analysis}

\subsubsection{Analysis of seed hill-feeding performance}

Effects of rapeseed varieties and rotational speed on seed feeding quantity were extremely significant (Table 5). The seed feeding quantity was reduced with the increase of rotational speed. The size of different rapeseed varieties resulted in the difference in seed feeding quantity. After particle's size increased, the seed number entered into the model-hole decreased. There was no significant difference in variance coefficient of seed feeding quantity of less than $17.0 \%$. This meant that the seed hill-feeding performance was stable for the seed hill-feeding device. The rotational speeds had significant impacts on the vertical hill diameter. The vertical hill diameter tended to be reduced with increasing rotational speed, which was affected by seed feeding quantity. Furthermore, the vertical hill diameter and its variance coefficient were less than $2.5 \mathrm{~cm}$ and $40 \%$, respectively. The variation coefficient of hill diameter was less than $8.0 \%$ with the hill spacing about $10 \mathrm{~cm}$. Combining the experiment results with seed hill-feeding distribution (Figure 13), it was observed that the hill's concentration and hill spacing's stability were beneficial to the uniform distribution.

Table 5 Experimental results of seed feeding for rapeseed

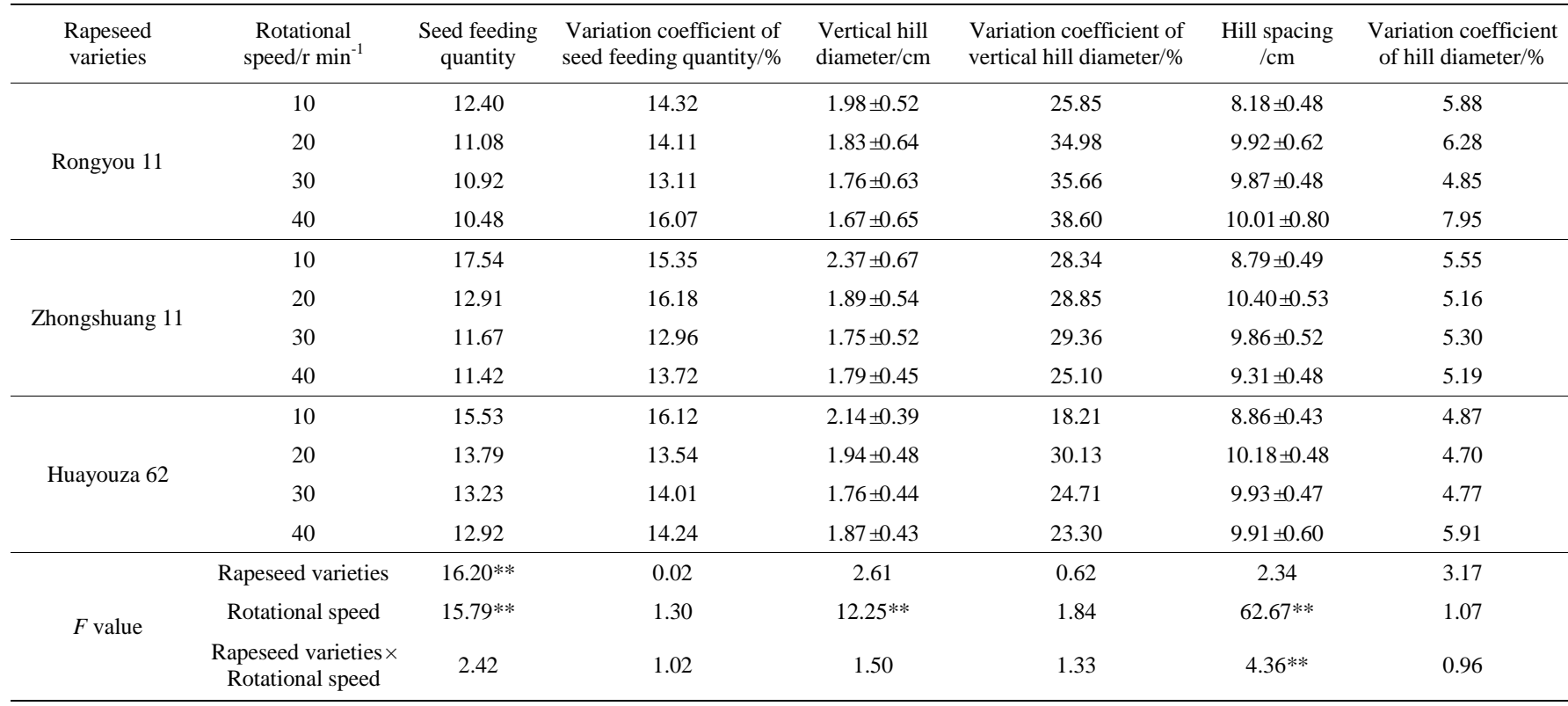




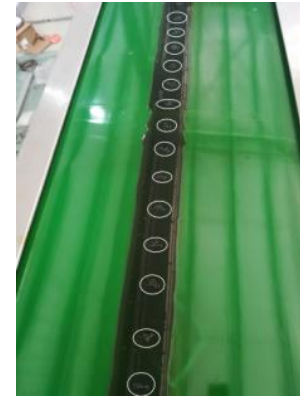

Figure 13 Hill distribution of rapeseed population

\subsubsection{Analysis of distribution performance}

The results showed that rapeseed varieties had a remarkable influence on seed feeding quantity in each row. Seed feeding quantity of Zhongshuang 11 was larger than those of Huyouza 62 and Rongyou 11 (Table 6). It was related to seed feeding quantity for different rapeseed varieties. Seed feeding quantity in each row increased with the increase of rotational speeds, but its variance coefficient decreased firstly and then increased. The seed feeding quantity in each row was consistent with its variance coefficient, which was less than $6.5 \%$.

The seeds' number ranged from 2 to 3 each hill, and hill diameter increased with the increase of rotational speed. There was a proper hilling performance with a hill diameter of less than $3.5 \mathrm{~cm}$. The hill spacing was stable at $10 \mathrm{~cm}$ and the variance coefficient of hill spacing was not more than $32.0 \%$ (Table 7). This indicated that the uniformity of feeding had good effect on rapeseed seeding, which realized the seeding patterns of concentrating and hilling (Figure 14). It was also observed that the seed position was affected by airflow disturbance and collision between seed and wall in the seed tube, which reduced the uniformity of seeding.

Table 6 Experimental results of apiece row consistency for rapeseed

\begin{tabular}{|c|c|c|c|c|c|c|c|c|c|}
\hline \multirow{2}{*}{$\begin{array}{l}\text { Rapeseed } \\
\text { varieties }\end{array}$} & \multirow{2}{*}{$\begin{array}{c}\text { Rotational } \\
\mathrm{speed} / \mathrm{r} \cdot \mathrm{min}^{-1}\end{array}$} & \multicolumn{6}{|c|}{ Seed feeding quantity each row/g. $\mathrm{min}^{-1}$} & \multirow{2}{*}{$\begin{array}{l}\text { Average seed feeding } \\
\text { quantity } / \mathrm{g} \cdot \mathrm{min}^{-1}\end{array}$} & \multirow{2}{*}{$\begin{array}{c}\text { Variation coefficient of } \\
\text { seeding quantity each } \\
\text { row } / \%\end{array}$} \\
\hline & & $1^{\text {st }}$ row & $2^{\text {nd }}$ row & $3^{\text {rd }}$ row & $4^{\text {th }}$ row & $5^{\text {th }}$ row & $6^{\text {th }}$ row & & \\
\hline \multirow{4}{*}{ Rongyou 11} & 10 & 1.31 & 1.26 & 1.23 & 1.12 & 1.15 & 1.15 & 1.20 & 6.10 \\
\hline & 20 & 2.67 & 2.56 & 2.43 & 2.30 & 2.30 & 2.35 & 2.44 & 6.20 \\
\hline & 30 & 3.63 & 3.29 & 3.24 & 3.15 & 3.28 & 3.47 & 3.34 & 5.22 \\
\hline & 40 & 4.63 & 4.47 & 4.26 & 4.20 & 3.98 & 4.25 & 4.30 & 5.27 \\
\hline \multirow{4}{*}{ Zhongshuang 11} & 10 & 1.68 & 1.57 & 1.58 & 1.50 & 1.45 & 1.59 & 1.56 & 5.05 \\
\hline & 20 & 3.10 & 2.94 & 2.92 & 2.77 & 2.71 & 2.91 & 2.89 & 4.78 \\
\hline & 30 & 4.28 & 4.03 & 4.06 & 3.95 & 3.78 & 4.02 & 4.02 & 4.07 \\
\hline & 40 & 5.46 & 5.12 & 5.18 & 4.82 & 4.93 & 5.08 & 5.10 & 4.32 \\
\hline \multirow{3}{*}{ Huayouza 62} & 10 & 1.61 & 1.54 & 1.51 & 1.40 & 1.40 & 1.47 & 1.49 & 5.54 \\
\hline & 20 & 2.80 & 2.66 & 2.52 & 2.48 & 2.65 & 2.63 & 2.62 & 4.31 \\
\hline & 40 & 4.85 & 4.57 & 4.54 & 4.41 & 4.60 & 4.40 & 4.56 & 3.55 \\
\hline
\end{tabular}

Table 7 Experimental results of seeding uniformity performance for rapeseed

\begin{tabular}{|c|c|c|c|c|c|}
\hline Rapeseed varieties & $\begin{array}{l}\text { Rotational speed } \\
\qquad / \mathrm{r} \cdot \mathrm{min}^{-1}\end{array}$ & $\begin{array}{l}\text { Seeds' number } \\
\text { each hill }\end{array}$ & $\begin{array}{l}\text { Hill diameter } \\
\text { /cm }\end{array}$ & $\begin{array}{l}\text { Hill spacing } \\
\text { /cm }\end{array}$ & $\begin{array}{l}\text { Variance coefficient of } \\
\text { hill spacing/\% }\end{array}$ \\
\hline \multirow{4}{*}{ Rongyou 11} & 10 & 2.26 & 1.68 & 9.45 & 28.83 \\
\hline & 20 & 2.28 & 2.33 & 10.01 & 28.86 \\
\hline & 30 & 2.06 & 1.81 & 9.51 & 31.73 \\
\hline & 40 & 2.11 & 2.04 & 10.34 & 31.23 \\
\hline \multirow{4}{*}{ Zhongshuang 11} & 10 & 2.84 & 2.59 & 9.18 & 25.85 \\
\hline & 20 & 2.46 & 2.53 & 9.58 & 26.13 \\
\hline & 30 & 2.69 & 2.72 & 10.68 & 25.60 \\
\hline & 40 & 2.77 & 3.12 & 10.90 & 29.00 \\
\hline \multirow{3}{*}{ Huayouza 62} & 10 & 2.36 & 2.10 & 9.54 & 26.12 \\
\hline & 20 & 2.00 & 1.98 & 9.78 & 29.56 \\
\hline & 30 & 2.01 & 1.83 & 9.63 & 30.21 \\
\hline
\end{tabular}

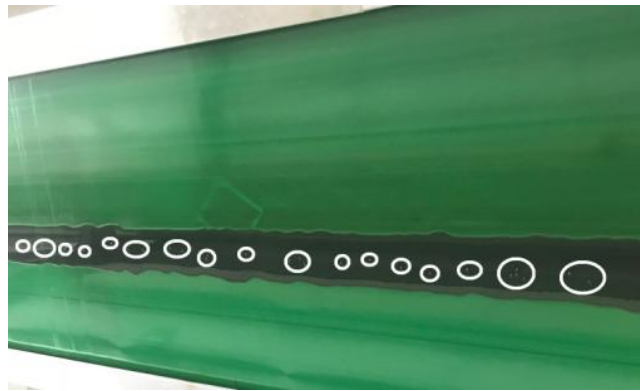

Figure 14 Seeding performance of rapeseed

\subsection{Field experiment results and analysis}

The field experiment of rapeseed sowing was conducted in the modern agricultural research and development base of Sichuan Agricultural University, Chongzhou City, Sichuan Province in 2018. The former stubble was rice with an average moisture content of $25.46 \%$. In the field experiment, the M954KQ tractor produced by Kubota Corporation was utilized as power and the processes of rotary tillage, precision seeding, fertilizing, riding ditch and chemical weeding were accomplished synchronously by the air-seeder with sowing 6 rows (Figure 15a). The rapeseed varieties included Huayouza 62, Zhongshuang 11 
and Rongyou 11, and the row spacing was $300 \mathrm{~mm}$. The growth of rapeseed at seedling and mature stages was shown in Figure 15.

In order to estimate seeding performance of air-seeder, the seedlings in each meter were measured for 6 rows. There are significant differences in the seedling number of three varieties of rapeseed (Table 8), and the seedlings' quantity ranged from 9 to 13 seedlings $/ \mathrm{m}$. The variance coefficient of the average seedling was less than $25.0 \%$. Though the seedlings' emergences are affected by soil moisture and seed germination rate, the seedlings' distribution was relatively uniform. The yield and components of rapeseed are listed in Table 9. The average yield reached $2761 \mathrm{~kg} / \mathrm{hm}^{2}$, which met the requirements of mechanized planting for rapeseed.

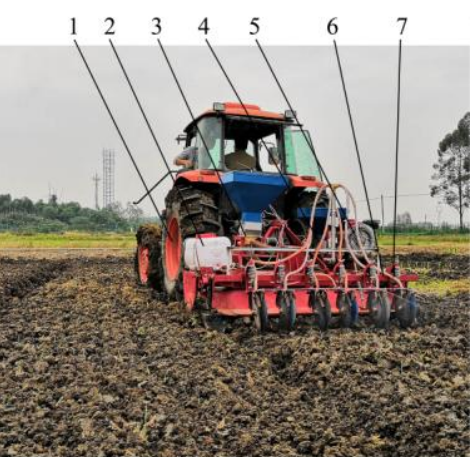

a. Field experiment of sowing

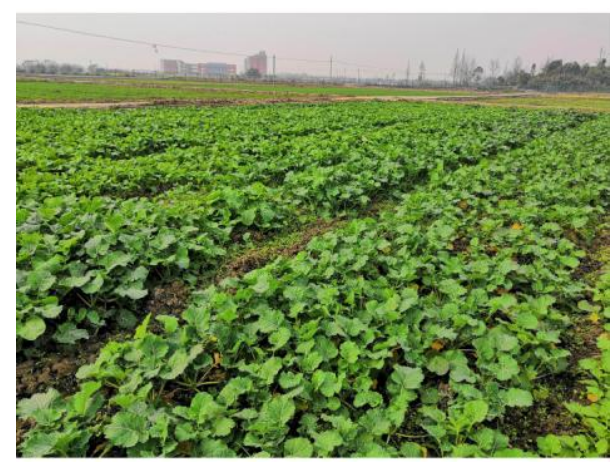

b. Growth in seedling stage

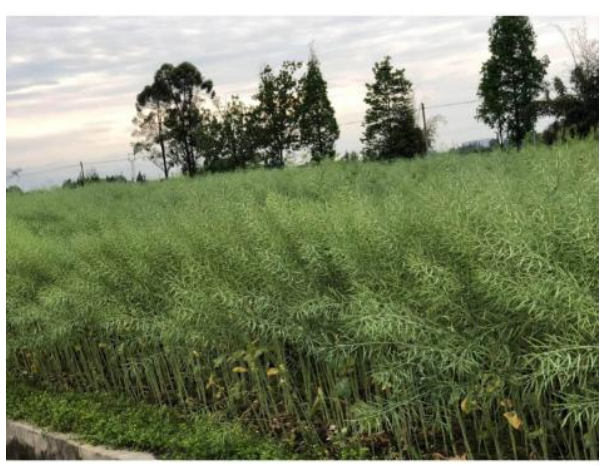

c. Growth in mature stage

6. Rotary tillage system 7. Weeding device

1. Tractor 2. Pesticide box 3. Fertilizer sowing device 4. Air-assisted centralized seed-metering device 5. Air pump

Figure 15 Field experiment and seedling for rapeseed

Table 8 Seedling emergence of rapeseed

\begin{tabular}{|c|c|c|c|c|c|c|c|c|}
\hline Rapeseed varieties & $1^{\text {st }}$ row & $2^{\text {nd }}$ row & $3^{\text {rd }}$ row & $4^{\text {th }}$ row & $5^{\text {th }}$ row & $6^{\text {th }}$ row & Average seedling & Variance coefficient of average seedling/\% \\
\hline \multirow{3}{*}{ Huayouza 62} & 9 & 10 & 9 & 8 & 11 & 8 & 9.2 & 12.8 \\
\hline & 8 & 8 & 7 & 10 & 12 & 10 & 9.2 & 20.0 \\
\hline & 9 & 12 & 9 & 8 & 10 & 11 & 9.8 & 15.0 \\
\hline \multirow{3}{*}{ Zhongshuang 11} & 10 & 11 & 12 & 11 & 14 & 16 & 12.3 & 18.3 \\
\hline & 10 & 9 & 16 & 15 & 12 & 12 & 12.3 & 22.2 \\
\hline & 8 & 10 & 10 & 8 & 7 & 11 & 9.0 & 17.2 \\
\hline \multirow{3}{*}{ Rongyou 11} & 8 & 8 & 11 & 11 & 9 & 10 & 9.5 & 14.5 \\
\hline & 9 & 13 & 8 & 13 & 9 & 13 & 10.8 & 22.2 \\
\hline & 13 & 15 & 10 & 10 & 10 & 9 & 11.2 & 20.7 \\
\hline
\end{tabular}

Table 9 Yield and its components of rapeseed

\begin{tabular}{|c|c|c|c|c|c|c|}
\hline Rapeseed varieties & Seedling density $/ \times 10^{4} \cdot \mathrm{hm}^{-2}$ & Branches & Number of pods & Seeds per pod & 1000 -grain mass/g & Yield $/ \mathrm{kg} \cdot \mathrm{hm}^{-2}$ \\
\hline Huayouza 62 & 28.2 & 7.4 & 138.67 & 25.21 & 3.44 & 2809.00 \\
\hline Zhongshuang 11 & 33.6 & 4.7 & 103.75 & 21.49 & 4.47 & 2642.50 \\
\hline Rongyou 11 & 31.5 & 6.5 & 123.50 & 20.10 & 4.41 & 2831.50 \\
\hline Average & 31.1 & 6.2 & 121.97 & 22.27 & 4.11 & 2761.00 \\
\hline
\end{tabular}

\section{Conclusions}

The seed motion simulation and the optimal structural parameters of air-assisted centralized seed-metering device were studied based on the numerical analysis. The distribution performance and seed position were analyzed using bench tests and field experiments. The conclusions were as follows:

1) Effects of structural parameters of involute type model-hole on seed feeding quantity and hill performance were investigated using EDEM simulation. The seed feeding quantity increased with the increase of model-hole's length, depth and section size. The variation coefficient of seed feeding quantity each hill and hill diameter were better with the model-hole's depth of $3.0 \mathrm{~mm}$, the type II model-hole and model-hole's length of $10 \mathrm{~mm}$. The seed population could be separated uniformly at almost the same spacing interval using the CFD-DEM coupling approach.

2) Rapeseed varieties and rotational speed had significant influence on seed feeding quantity and the variance coefficient of seed feeding quantity was less than $17.0 \%$. The hill diameter was less than $3.5 \mathrm{~cm}$ and reduced with the increase of rotational speed. The variation coefficient of seeding quantity in each row and seeding uniformity was less than $6.5 \%$ and $32.0 \%$, respectively, which realized the seeding patterns of concentrating and hilling.

3) The field experimental results indicated that the seedlings' quantity ranged from 9 to 13 seedlings per meter for the rapeseed varieties of Rongyou 11, Zhongshuang 11 and Huayouza 62. The variance coefficient of average seedling was less than $25.0 \%$ and the average yield reached $2761 \mathrm{~kg} / \mathrm{hm}^{2}$, which met the requirements of rapeseed mechanized planting.

\section{Acknowledgements}

The authors acknowledge that this work was financially supported by the National Natural Science Foundation of China (Grant No. 31901413) and the National Key Project of Research and Development Program, Ministry of Science and Technology of the People's Republic of China (Grant No. 2018YFD0301204). 


\section{[References]}

[1] Wang H Z, Yin Y. Analysis and strategy for oil crop industry in China. Chinese Journal of Oil Crop Sciences, 2014; 36(3): 414-421. (in Chinese)

[2] Liao Q X, Lei X L, Liao Y T, Ding Y C, Zhang Q S, Wang L. Research progress of precision seeding for rapeseed. Transactions of the CSAM, 2017; 48(9): 1-16. (in Chinese)

[3] Kumar V J F, Durairaj C D. Influence of head geometry on the distributive performance of air-assisted seed drills. Journal of Agricultural Engineering Research, 2000; 75(1): 81-95.

[4] Yatskul A, Lemiere J P, Cointult F. Influence of the divider head functioning conditions and geometry on the seed's distribution accuracy of the air-seeder. Biosystems Engineering, 2017; 161: 120-134.

[5] Yatskul A, Lemiere J P. Establishing the conveying parameters required for the air-seeders. Biosystems Engineering, 2018; 166: 1-12.

[6] Mudarisova S, Badretdinova I, Rakhimov Z, Lukmanov R, Nurullin E. Numerical simulation of two-phase "Air-Seed" flow in the distribution system of the grain seeder. Computers and Electronics in Agriculture, 2020; 168, 105151

[7] Chang J L, Zhang X H. Design and test of one-step centralized type pneumatic seeding system. Transactions of the CSAE, 2011; 27(1): 136-141. (in Chinese)

[8] Zhang X H, Wang Y Z, Zhang L, Peng C J, Fan G J. Design and experiment of wheat pneumatic centralized seeding distributing system. Transactions of the CSAM, 2018; 49(3): 59-67. (in Chinese)

[9] Li Z H, Wang D C, Liu G L, Yang M S, Wang Z H. Experimental study on sowing seeds by air-stream metering mechanism. Transactions of the CSAE, 2009; 25(1): 89-93.

[10] Li Z H, Wang D C, Liu G L, Yang M S, Wang Z H. CFD Simulation and improvement of air stream distributive metering device. Transactions of the CSAM, 2009; 40(3): 64-68. (in Chinese)

[11] Dai Y Z, Luo X W, Wang Z M, Zeng S, Zang Y, Yang W W, et al. Design and experiment of rice pneumatic centralized seed distributor. Transactions of the CSAE, 2016; 32(24): 36-42. (in Chinese)

[12] Zhao J H, Liu L J, Yang X J, Du J W, Zhao Z B. Design and experiment of pneumatic seeding system of teff seeder. Transactions of the CSAM, 2018; 49(S1): 101-107. (in Chinese)

[13] Qi B, Zhang W Y, Yu S S, Ji Y, Li K, Zhang S Y. Establishment of seeding amount control model for centralized pneumatic metering system for rice. Transactions of the CSAM, 2018; 49(S1): 125-131. (in Chinese)

[14] Yu X R, Geng D Y, Du R C, Jin C L, Yang S D, Lu X F. Design and experiment of wheat planter by pneumatic conveying with no-tillage. Transactions of the CSAM, 2018; 49(s1): 141-148. (in Chinese)

[15] Wang B L, Luo X W, Wang Z M, Zheng L, Zhang M H, Dai Y Z, Xing H Design and field evaluation of hill-drop pneumatic central cylinder direct-seeding machine for hybrid rice. Int J Agric \& Biol Eng, 2018; 11(6): 33-40.

[16] Lei X L, Liao Y T, Li Z D, Cao X Y, Li S S, Wei Y P, Liao Q X. Design and experiment of seed feed device in air-assisted centralized metering device for rapeseed and wheat. Transactions of the CSAE, 2015; 31(20): 10-18. (in Chinese)

[17] Lei X L, Liao Y T, Li Z D, Zhang W Y, Cao X Y, Li S S, et al. Effects of seed layer thickness on seed filling performance of seed feeding device for rapeseed and wheat. Transactions of the CSAE, 2016; 32(6): 11-19. (in Chinese)

[18] Lei X L, Liao Y T, Liao Q X. Simulation of seed motion in seed feeding device with CFD-DEM coupling approach for rapeseed and wheat. Computers and Electronics in Agriculture, 2016; 131, 29-39.

[19] Lei X L, Liao Y T, Wang L, Wang D, Yao L, Liao Q X. Simulation of gas-solid two-phase flow and parameter optimization of pressurized tube of air-assisted centralized metering device for rapeseed and wheat. Transactions of the CSAE, 2017; 33(19): 67-75. (in Chinese)

[20] Lei X L, Liao Y T, Zhang Q S, Wang L, Liao Q X. Numerical simulation of seed motion characteristics of distribution head for rapeseed and wheat. Computers and Electronics in Agriculture, 2018; 150: 98-109.

[21] Lei X L, Liao Y T, Cong J L, Wang L, Zhang Q S, Liao Q X. Parameter optimization and experiment of air-assisted centralized seed-metering device of direct seeding machine for rape and wheat. Transactions of the CSAE, 2018; 34(12): 16-26. (in Chinese)

[22] Lei X L, Yang W H, Yang L J, Liu L Y, Liao Q X, Ren W J. Design and experiment of seed hill feeding device in pneumatic centralized metering device for hybrid rice. Transactions of the CSAM, 2018; 49(11): 58-67. (in Chinese)

[23] Norma, ISO 7256/2, 1984. Sowing equipment-test methods-seed drills for sowing in lines. 